\title{
Do climate and soil influence phenotypic variability in leaf litter, microbial decomposition and shredder consumption?
}

\author{
M. A. S. Graça • J. M. Poquet
}

Received: 6 May 2013 / Accepted: 29 October 2013 / Published online: 13 November 2013

(C) Springer-Verlag Berlin Heidelberg 2013

\begin{abstract}
We tested the hypothesis that water stress and soil nutrient availability drive leaf-litter quality for decomposers and detritivores by relating chemical and physical leaf-litter properties and decomposability of Alnus glutinosa and Quercus robur, sampled together with edaphic parameters, across wide European climatic gradients. By regressing principal components analysis of leaf traits [N, P, condensed tannins, lignin, specific leaf area (SLA)] against environmental and soil parameters, we found that: (1) In $Q$. robur the condensed tannin and lignin contents increased and SLA decreased with precipitation, annual range of temperature, and soil $\mathrm{N}$ content, whereas leaf $\mathrm{P}$ increased with soil $\mathrm{P}$ and temperature; (2) In A. glutinosa leaves N, P, and SLA decreased and condensed tannins increased with temperature, annual range of temperature, and decreasing soil P. On the other hand, leaf P and condensed tannins increased and SLA decreased with minimum annual precipitation and towards sites with low temperature. We selected contrasting leaves in terms of quality to test decomposition and invertebrate consumption. There were intraspecific differences in microbial decomposition rates (field, $Q$. robur) and consumption by shredders (laboratory, A. glutinosa). We conclude that decomposition rates across ecosystems could be partially governed by climate and soil properties, affecting litter quality and therefore
\end{abstract}

Communicated by Robert O. Hall.

Electronic supplementary material The online version of this article (doi:10.1007/s00442-013-2825-2) contains supplementary material, which is available to authorized users.

M. A. S. Graça $(\bowtie) \cdot$ J. M. Poquet

IMAR-CMA and Department of Life Sciences, University

of Coimbra, Coimbra, Portugal

e-mail: mgraca@ci.uc.pt decomposers and detritivores. Under scenarios of global warming and increased nutrients, these results suggest we can expect species-specific changes in leaf-litter properties most likely resulting in slow decomposition with increased variance in temperatures and accelerated decomposition with P increase.

Keywords Litter breakdown - Detritivores - Headwaters . Leaf traits

\section{Introduction}

Globally, most of the energy fixed by primary producers will enter detrital pathways, fueling what has been termed "brown food webs" (Kaspari et al. 2008). Decomposition of organic matter is therefore an important ecosystem process, with a pivotal role in the global $\mathrm{C}$ cycle.

In most streams, the standing stock of detrital organic matter can be several times larger than the biomass of producers, and respiration is assumed to exceed primary production (Abelho 2001). This relatively high biomass of organic matter occurs because the headwaters are usually shaded by riparian vegetation, reducing the amount of solar energy reaching in-stream primary producers. Riparian vegetation also subsidizes streams with leaf litter and other plant detritus, used as energy sources by consumers. Given the high proportion of low-order streams in fluvial hydrological networks [up to $85 \%$ of the total stream length in a basin (Allan and Castillo 2007)], allochthonous inputs of organic matter from the riparian zone and its decomposition play an important role in riverine nutrient cycling, including the incorporation of nutrients into fluvial food webs.

Litter decomposition is mainly a biological process involving fungi, bacteria and invertebrate shredders (Graça 
2001; Krauss et al. 2011). The combined action of microorganisms and invertebrates produces fine particulate organic matter which is further used as food by filterers and gatherers. The rate at which litter material is incorporated into brown food webs is influenced by leaf traits, such as nutrient content (mainly $\mathrm{N}$ and $\mathrm{P}$ ), leaf toughness, and plant chemical defenses (Cornwell et al. 2008; Graça and Cressa 2010; Pennings et al. 1998).

Leaf traits are selected in response to local environmental conditions including soil nutrient availability and climate, particularly temperature and water availability (Reich and Oleksyn 2004). Plants from drier areas tend to have thicker leaves, whereas plants from nutrient-rich soils tend to have higher leaf $\mathrm{N}$ and $\mathrm{P}$ contents than species from nutrient-poor soils (interspecific variability; Chen et al. 2011; Cunningham et al. 1999; Ordoñez et al. 2009; Wright et al. 2001).

If plant species are distributed across heterogeneous environments and if climate and soils are important drivers of leaf traits, including leaf quality, then intraspecific variability in leaf chemical and physical properties should be expected in addition to the enormous interspecific variability among plants. Plants of the same species affected by different environmental conditions should differ in their leaf (and litter) traits and quality. Intraspecific differences in litter decomposition were shown by Lecerf and Chauvet (2008), who reported that leaf litter of black alder [Alnus glutinosa (L.) Gaertn.] from different areas differed in terms of $\mathrm{P}$ and lignin leaf content, which were correlated with decomposition rates.

The environment-leaf trait—litter decomposition relationship is also important in the context of global changes. Two of such changes are relevant in the context of our research. Firstly, nutrients in soil and waters are increasing worldwide due to increasing arable land and atmospheric deposition (e.g., Rockström et al. 2009; Vitousek et al. 1997). The disruption of the $\mathrm{N}$ cycle ranks second among the most threatened planetary systems for which the safe boundary for humans has already been transgressed according to Rockström et al. (2009) and the disruption of the $\mathrm{P}$ cycle is also among the nine most affected systems. Secondly, climate change due to $\mathrm{CO}_{2}$ atmospheric increases is predicted to result in increased temperatures, decreased precipitation and high variability in both, temperature and precipitation (IPCC 2007). Climate change is considered to be the second most important planetary disruption according to Rockström et al. (2009). These ongoing changes may drive the selection of important leaf traits and have the potential to affect litter dynamics and nutrient cycling.

Here we tested the hypothesis that the environmental factors of water stress and soil nutrient availability drive leaf quality for decomposers and detritivores. By using the same two plant species from areas that differ in environmental conditions, we controlled for species-specific traits; however, within-species genetic variability was an unmeasured component of phenotypic variability. The hypothesis was tested with respect to chemical and physical leaf-litter properties and decomposability of two European deciduous tree species, black alder A. glutinosa and pedunculate oak Quercus robur L., sampled across Europe, over a range of climatic and edaphic gradients. We expected that:

1. Plants from sites with high air temperatures and low precipitation would produce poorer quality leaves (high toughness and low nutrient content) than those exposed to milder environmental conditions.

2. Plants growing on nutrient-poor soils (low $\mathrm{N}$ and $\mathrm{P}$ content) would produce poorer quality leaves with a lower nutrient content than plants grown in nutrientrich soils.

3. For the same species, low-quality leaves would decompose at slower rates than high-quality leaves.

4. For the same species, low-quality leaves would be consumed by shredder invertebrates at lower rates than high-quality leaves.

These two final hypotheses were tested with two types of leaves per species that contrasted in terms of $\mathrm{P}, \mathrm{N}$, condensed tannin and lignin content and specific leaf area (SLA).

\section{Materials and methods}

Leaf, environmental and soil data

To test whether environmental conditions affect leaf traits controlling decomposition, senescent leaves were taken from individual trees of black alder (Alnus glutinosa (L.) Gaertn.; 57 locations) and pedunculate oak (Quercus robur L.; 39 locations) across Europe [Fig. 1; Table A1, Electronic supplementary material (ESM)]. Leaves and soil samples $(\sim 10 \mathrm{~cm}$ below the leaf litter accumulations and under each individual tree) were collected in autumn 2010. The samples of soil and senescent leaves were air-dried and stored until needed. Soil samples were passed through a 1-mm mesh screen and analyzed for $\mathrm{pH}, \mathrm{N}$ and $\mathrm{P}$ content (ascorbic acid method) (Doran and Jones 1996).

For each sampling site, the minimum, maximum, and mean annual temperature, and the annual range of temperature, as well as mean annual precipitation, minimum annual precipitation and annual range of precipitation were obtained by combining the sites' geographical coordinates with the WorldClim database version 1.3 (Hijmans 
Fig. 1 Sampling sites across Europe for oak (Quercus robur, $n=39$ ) and alder (Alnus glutinosa, $n=57$ ). Natural distribution of species in gray (EUFORGEN 2009 distribution maps; www.euforgen.org)
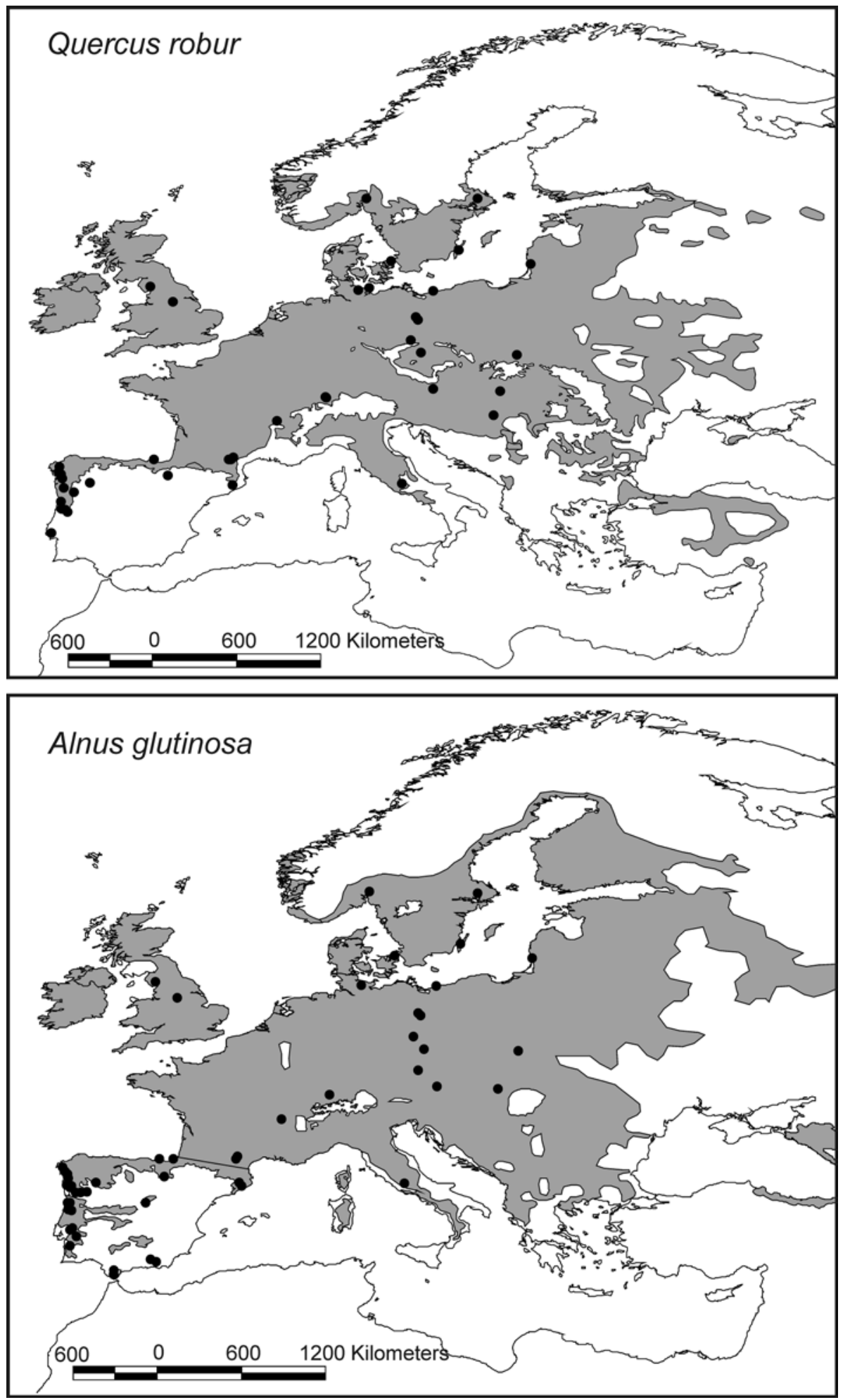

et al. 2005) at the highest resolution (2.5 min of arc), by means of the DIVA-GIS software, version 7.1.7 (http://www.diva-gis.org). Data for the Global Aridity Index and global potential evapo-transpiration were obtained from Trabucco and Zomer (2009).
Leaf traits

For each leaf sample, several morphological and chemical leaf traits were measured and analyzed. SLA (leaf area/ leaf dry mass) was determined by weighing $( \pm 0.01 \mathrm{mg})$ 
three leaf disks obtained with a cork borer (14 mm diameter), from four randomly chosen leaves in each leaf sample (total $3 \times 4=12$ leaf discs). $\mathrm{P}, \mathrm{N}$, lignin and condensed tannins were measured from leaf powder. Three grams of leaves from each sample was ground to powder (1-mm screen, Retsch ZN 100; Haan, Germany) and stored in an oven at $60{ }^{\circ} \mathrm{C}$ until needed. $\mathrm{N}$ leaf content was determined in a Perkin Elmer 2400 Series II CHNS/O analyzer (Perkin Elmer, Boston, MA). P was analyzed by the reactive soluble P (RSP) determination technique [(Eaton et al. 1995); with leaf powder samples previously submitted to a basic digestion to convert all $\mathrm{P}$ in the sample to RSP]. Lignin content was analyzed as described by Goering and Van Soest (1970) (Klason lignin). The content of condensed tannins was obtained by the acid butanol assay (Gessner and Steiner 2005).

Environment and leaf-quality relationship: statistical procedures

To investigate leaf-quality gradients, we performed a principal components analysis (PCA) based on a variable correlation matrix with the standardized morphological and chemical leaf-trait variables for both oak and alder. Previously, we checked the data with the Kolmogorov-Smirnov test for normality, and no transformation was needed for any variable. Both PCAs were performed with STATISTICA software version 7.1 (StatSoft 2005).

Once the leaf-quality gradients for each species were defined, we used them as response variables in multiple regression analyses to relate leaf quality to uncorrelated and standardized environmental and soil parameters. Unlike leaf quality, data for soil nutrient content were transformed by natural logarithms to achieve normality. We applied information theory for model selection and multimodel inference, and used the second-order Akaike information criterion (AICc) to select the best subset of regression models from among all the possible combinations of standardized environmental and soil variables. AIC is a measure of the relative quality of a statistical model; it offers a relative estimate of the information lost when a model is used to represent the process that generates the data. AICc is a modification of the former, recommended for situations with a small sample size compared to the number of parameters (Burnham and Anderson 2002). We limited our regression models to six and four variables at most, for alder and oak, respectively (Quinn and Keough 2002).

We calculated the AICc for all models, and sorted them according to their AICc to rank the candidate models by calculating the AICc increase in relation to the best model with the minimum AICc $\left(\Delta_{\mathrm{i}}=\mathrm{AICc}_{\mathrm{i}}-\mathrm{AICc}_{\text {min }}\right)$. As suggested by Burnham and Anderson (2002) we selected only those models with $\Delta_{\mathrm{i}} \leq 2$. We then calculated the AICc weights $\left(\omega_{i}\right)$ as the probability of each model being the best model, and the evidence ratio $\left(\mathrm{ER}=\omega_{\min } / \omega_{j}\right)$, which is the relative likelihood of the best model $\left(\omega_{\min }\right)$ versus any model $\left(\omega_{j}\right)$.

We also calculated the variable relative importance (VRI) by summing the AICc weights across all the models in the set where each variable occurs. The larger the VRI value, the more important the variable is in relation to the others. Finally, we used model averaging to calculate the corresponding parameter estimates $(\beta)$. For each environmental variable in the selected subset of models, we summed the $\beta$-values, weighted by the corresponding $\omega_{i}$ for those models in which that variable was present, across the whole set of models (Burnham and Anderson 2002). All the multiple regression models were developed using $\mathrm{R}$ software (R Development Core Team 2008).

\section{Decomposition}

Four leaf samples representing the extremes of the leafquality gradients for both alder and oak were selected to perform an experiment on microbial decomposition and consumption by shredders. To determine how phenotypic differences in litter quality influence microbial decomposition rates, we incubated leaf bags $(0.5-\mathrm{mm}$ mesh size $)$ in a 3rd-order circumneutral stream in Candal, Lousã, Portugal [Portuguese site and sites $3 \mathrm{a}$ and $\mathrm{C} 1$, respectively, in Ferreira et al. (2012); Graça et al. (2001); Gulis et al. (2006)]. For each sample (two leaf species and two qualities), eight replicates were set, with $0.50 \pm 0.05 \mathrm{~g}$ (dry mass) of leaves each (two to four leaves). All bags were tied to iron bars anchored in the stream bed. Three replicates of each sample were retrieved after $10 \mathrm{~min}$, placed individually in plastic bags and transported to the laboratory in an insulated box, to account for transport and handling and to correct for airdried oven dry mass (Bärlocher 2005). The remaining 20 samples were left in the stream for 17 days (6-23 October 2011) and recovered just before heavy rains reached the study site. In previous experiments in the same stream and same season, by day 17 alder leaves had already reached the maximum fungal biomass $\left(110-145 \mathrm{mg}\right.$ of fungi $\mathrm{g}^{-1}$ leaf biomass), whereas oak leaves attained approximately $64 \%$ of maximum fungal biomass (91-55 $\mathrm{mg}$ of fungi $\mathrm{g}^{-1}$ leaf biomass); by the same date spore production from fungi in leaves was high (Ferreira et al. 2012; Gulis et al. 2006).

After collection, the leaf bags were individually transported to the laboratory in plastic Ziploc bags, gently washed with deionized water, and dried at $60{ }^{\circ} \mathrm{C}$ until constant weight. The samples were then weighed to the nearest $0.1 \mathrm{mg}$. Mass loss was expressed as a percentage, and intraspecific high- and low-quality leaf samples were 
compared by $t$-tests for independent samples performed with STATISTICA software version 7.1 (StatSoft 2005).

\section{Leaf consumption by shredders}

The effects of variation in leaf quality were also evaluated by measuring the feeding rates of a shredder on the four selected leaf types. We used the shredder caddisfly Schizopelex festiva (Rambur 1842; Trichoptera: Sericostomatidae). One hundred and twelve individuals were collected from the Múceres stream, a nutrient-rich mountain stream [see Gulis et al. (2006) for description]. This species was selected because it was locally abundant during the experimental season (October 2011) and is an active shredder. Individuals were acclimated to laboratory conditions for 3 days prior to the experiment, with a mixture of leaves from their original stream.

Feeding trials on the four treatments (alder, high and low quality; and oak, high and low quality) were carried out in plastic cups. A total of 64 cups were set. Of these, 16 were used as controls with leaves but no trichopterans (four replicates per treatment). We covered the bottom of the cups with a $0.5-\mathrm{cm}$-thick layer of stream sediment $(1-2 \mathrm{~mm})$, previously incinerated in a muffle furnace for $6 \mathrm{~h}$ at $500{ }^{\circ} \mathrm{C}$. Each cup was filled with approximately $200 \mathrm{ml}$ of stream water and oxygenated with an air pump.

For each leaf treatment, 12 leaf disks were randomly obtained with a cork borer (14 $\mathrm{mm}$ diameter) from leaves. Disks were conditioned during 5 days with a mixture of decomposing leaves from the Candal stream, in an aquarium with stream water highly oxygenated with an air pump. After conditioning, leaf disks were oven-dried at $50{ }^{\circ} \mathrm{C}$ until they reached constant weight, and weighed to the nearest $0.01 \mathrm{mg}$ to obtain the initial weight $\left(W_{i}\right)$. The short incubation time and dry/rehydration process were used to minimize the fungal effects on the intrinsic quality of leaves.

Forty-eight S. festiva individuals of similar size (1.76$2.12 \mathrm{~mm}$ case opening) were randomly and individually allocated to the cups and kept with no food for $24 \mathrm{~h}$ prior to the experiment. Consumption was allowed for 8 days (18-26 October 2011). After the feeding trial, the remains of the leaf disks were oven-dried at $50{ }^{\circ} \mathrm{C}$ to constant weight and were weighed to the nearest $0.01 \mathrm{mg}$ to obtain the final weight $\left(W_{\mathrm{f}}\right)$. The caddisfly case openings were also measured, at the beginning and the end of the feeding trials to indirectly obtain the size of the individuals and growth. The remaining 48 individuals of $S$. festiva that were not used in the experiments were dried and weighed, to relate the case opening to their dry mass by regression $\left[r^{2}=0.7816 ; P \leq 0.0001\right.$; weight $(\mathrm{mg})=-2.5818+2.1138 \times$ case opening width $(\mathrm{mm})]$.

Consumption $(C)$ was estimated as the differences in leaf mass exposed to the shredders $\left(W_{\mathrm{i}}, W_{f}\right)$, corrected for changes in the control $k$, given by the ratio of initial $\left(W_{\text {ic }}\right)$ and final $\left(W_{\mathrm{fc}}\right)$ mass in the control disks $\left(k=W_{\mathrm{ic}} / W_{\mathrm{fc}}\right)$, divided by the elapsed time $(t)$ and the mass $\left(W_{\mathrm{s}}\right)$ of the shredders (Canhoto et al. 2005):

$C=\frac{\left(\mathrm{W}_{\mathrm{i}}\right)-\left(\mathrm{W}_{\mathrm{f}} \times k\right)}{\left(t \times E_{\mathrm{s}}\right)}$.

The consumption rates of S. festiva showed heterogeneity of variance, and no data transformation improved their homoscedasticity. We compared the intraspecific consumption rates for both plant species (oak, high and low quality; and alder, high and low quality) by Welch's $t$-test. This is a robust analysis that allows hypothesis testing using data with unequal variances (Quinn and Keough 2002). This analysis was carried out with the JMP software version 7.0 (SAS 2007).

\section{Results}

Environment and leaf-quality relationship

The trees providing litter for the experiments occur across a wide range of conditions in Europe, particularly in terms of temperature (mean range $5.8-15.8{ }^{\circ} \mathrm{C}$ for oak and 5.1-16.9 ${ }^{\circ} \mathrm{C}$ for alder), mean annual precipitation (range 42.3-108.1 mm for oak and 31.5-114.0 mm for alder), and evapotranspiration (range 540.0-1,121.0 mm year ${ }^{-1}$ for oak and $540.0-1,155.0 \mathrm{~mm} \mathrm{year}^{-1}$ for alder; ESM, Table A2). Geographically, the samples covered almost the entire geographic distribution range of the two species in Europe; only the eastern part of the range was missing. With respect to soil, the $\mathrm{pH}$ ranged from 4.0 to 8.0, with $>50 \%$ of the sites within $\mathrm{pH} 5-7$. The range of soil $\mathrm{P}$ content was very similar for oak (7-200 $\mathrm{mg} \mathrm{kg}^{-1}$ ) and alder (11-200 $\mathrm{mg} \mathrm{kg}^{-1}$ ) sites, but $\mathrm{N}$ soil content was higher and more variable for alder (range $0.1-511 \mathrm{mg} \mathrm{kg}^{-1}$ ) than for oak sites (range $0.2-242 \mathrm{mg} \mathrm{kg}^{-1}$ ).

Both species were similar in terms of the leaf traits of $\mathrm{P}$ content (mean 0.09 and $0.07 \%$ for oak and alder, respectively), lignin (mean 36 and $33 \%$ for oak and alder, respectively) and SLA ( $15 \mathrm{~mm}^{2} \mathrm{mg}^{-1}$ for both species; Table 1). However, $\mathrm{N}$ was 2.3 -fold higher in alder than oak leaves, whereas condensed tannins were $\sim 75 \%$ lower (Table 1 ). Both species exhibited wide variations in the measured leaf traits.

The PCA of oak litter chemical and physical properties resulted in biplots in which the first three PCA axes explained $77 \%$ of the variation in the dataset (Fig. 2). PCA axis 1 (oak-PCA1) was positively correlated with lignin $(r=0.79)$ and condensed tannins $(r=0.89)$ and negatively correlated with the SLA $(r=-0.65$ ). PCA axis 2 (oakPCA2) was positively correlated with the leaf $\mathrm{P}$ content 
Table 1 Mean, SD, minimum (Min.) and maximum (max.) values of several quality parameters of oak and alder Europe

$D M$ Dry matter senescent leaves sampled across

\begin{tabular}{lrlllllll}
\hline & \multicolumn{1}{l}{ Oak } & & & & Alder & \\
\cline { 2 - 3 } Quality parameters & Mean & SD & & Min.-max. & & Mean & SD & Min.-max. \\
\hline P leaf content (\%DM) & 0.09 & 0.07 & $0.01-0.35$ & & 0.07 & 0.03 & $0.02-0.15$ \\
N leaf content (\%DM) & 1.03 & 0.41 & $0.56-2.13$ & & 2.33 & 0.35 & $1.38-2.98$ \\
Condensed tannins leaf content (\%DM) & 13.53 & 8.98 & $1.78-40.83$ & & 3.30 & 2.20 & $0.20-10.28$ \\
Lignin leaf content (\%DM) & 38.50 & 4.68 & $29.20-48.23$ & & 33.04 & 4.15 & $23.68-44.59$ \\
Specific leaf area $\left(\mathrm{mm}^{2} \mathrm{mg}^{-1}\right)$ & 14.57 & 3.93 & $0.01-25.79$ & & 15.44 & & 4.47 & $8.58-34.93$ \\
\hline
\end{tabular}

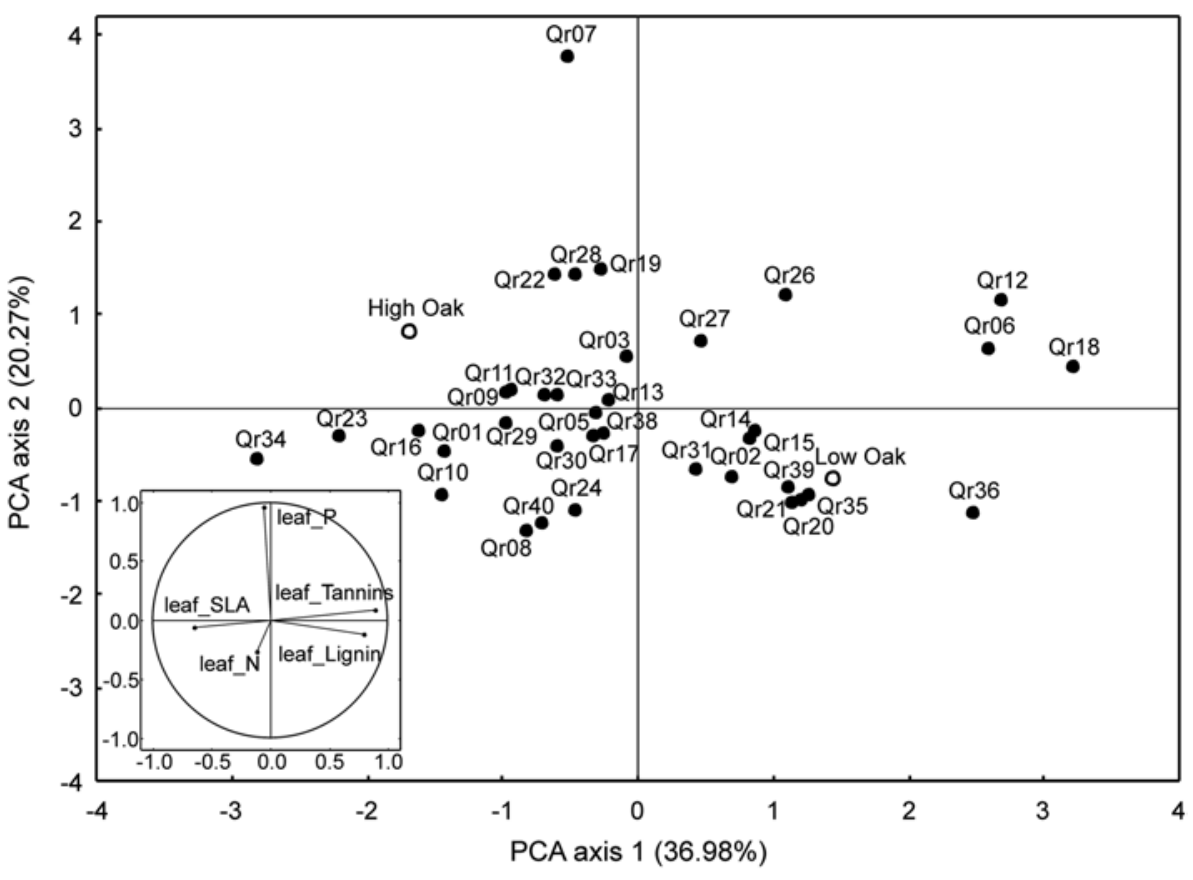

Fig. 2 Ordination of oak $(Q$. robur; $Q r$ ) sampling sites for the first three principal component analysis $(P C A)$ axes, based on the leaf-trait variables. Open circles denote those sampling sites from which leaves were used in the decomposition and consumption experiments as high (Qr04) and low (Qr37) leaf-litter quality. See the codes in Electronic supplementary material (ESM) Table A1 for the origin of samples

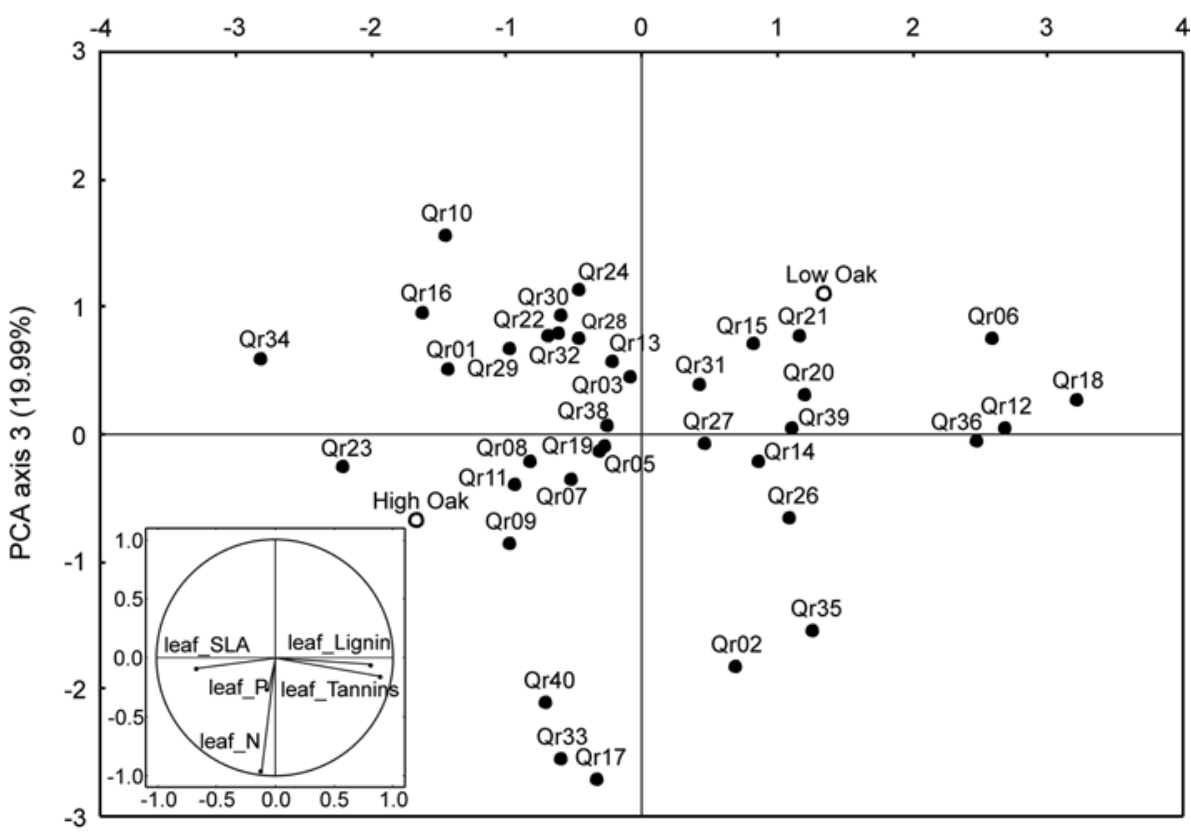


( $r=0.96$ ), and PCA axis 3 (oak-PCA3) was negatively correlated with leaf $\mathrm{N}$ content $(r=-0.95)$. For alder, the first three PCA axes explained $85 \%$ of the variation in the dataset (Fig. 3). In this case, PCA axis 1 (alder-PCA1; $39 \%$ of the variation) was negatively correlated with the leaf contents of $\mathrm{N}(r=-0.84)$ and $\mathrm{P}(r=-0.64)$, and positively correlated with condensed tannins $(r=0.61)$. PCA axis 2 (alder-PCA2) was also positively correlated with the leaf $\mathrm{P}$ content $(r=0.67)$, as well as with condensed tannins $(r=0.63)$. Both axes were negatively correlated with SLA $(r=-0.61)$. Finally, PCA axis 3 (alder-PCA3) was positively correlated with lignin leaf content $(r=0.94)$.

Multiple regression models revealed relationships between leaf quality and environmental parameters. For oak, the oak-PCA1 axis (increased tannins and lignin and decreased SLA) increased with soil $\mathrm{pH}$, mean annual precipitation, and annual range of temperature and $\mathrm{N}$ in soil (the highest VRI values; Table 2). The oak-PCA2 axis (surrogate of leaf $\mathrm{P}$ content) was positively related to soil $\mathrm{P}$ content and mean annual temperature. Finally,
Fig. 3 Ordination of alder (Alnus glutinosa; $A g$ ) sampling sites for the first three PCA axes, based on leaf-trait variables. Open circles denote those sampling sites from which leaves were used in the decomposition and consumption experiments as high $(\mathrm{Ag} 12)$ and low (AgO7) leaf-litter quality. See the codes in ESM (Table A1) for the origin of samples
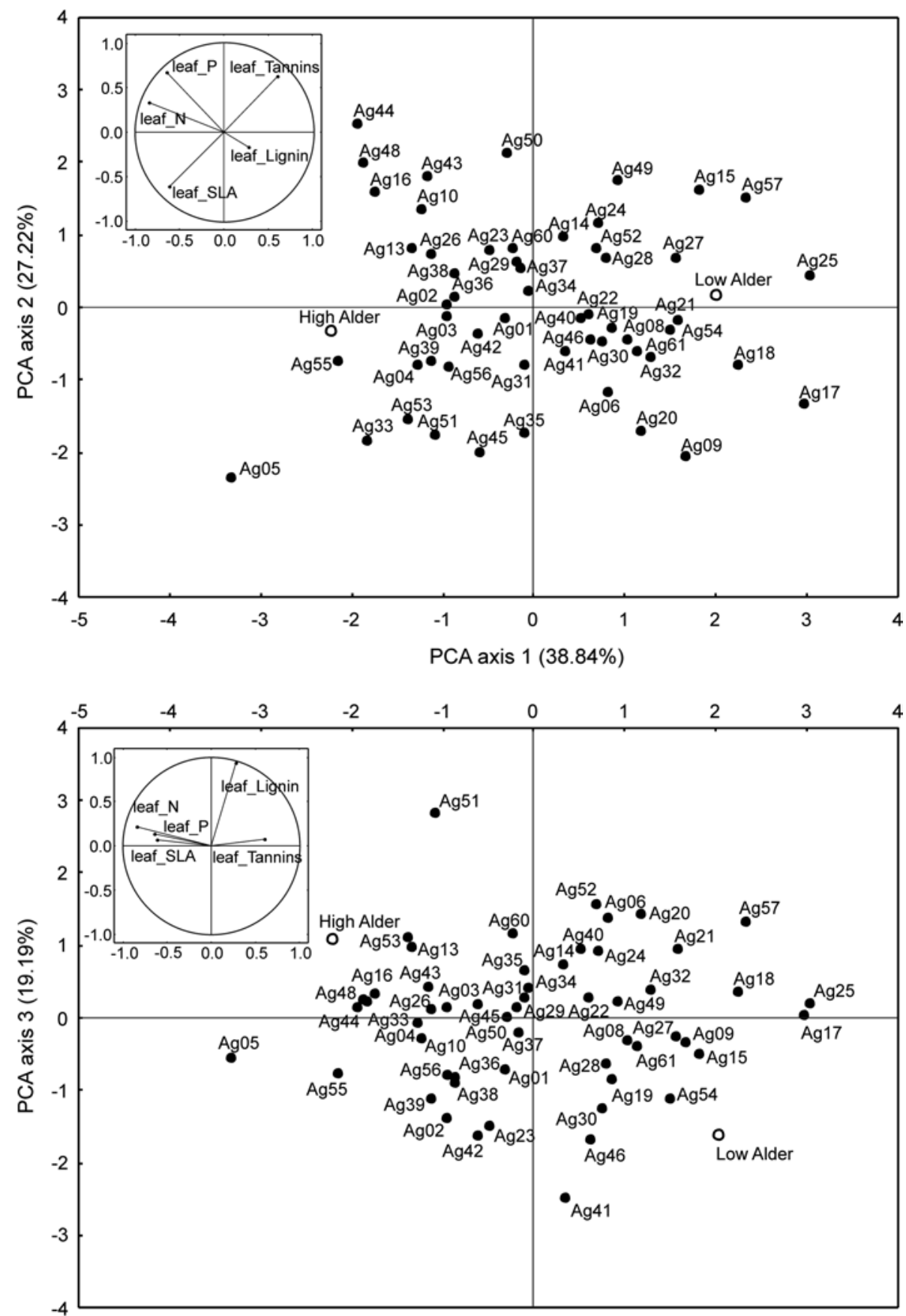


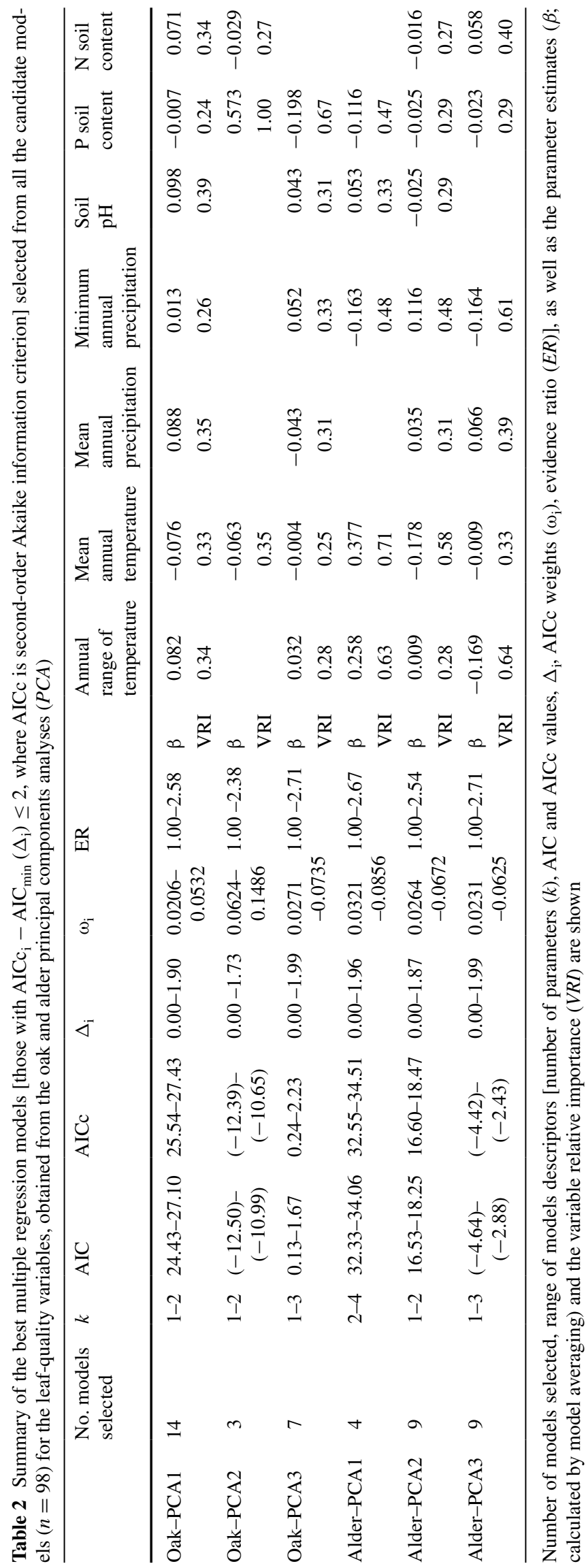


the oak-PCA3 axis (surrogate of the leaf $\mathrm{N}$ content) also increased with soil $\mathrm{P}$ content.

For alder leaves, the alder-PCA1 axes (decreased N, P, SLA and increased leaf condensed tannins) were positively related to the mean annual temperature and the annual range of temperature, and negatively related to the minimal annual precipitation and soil P. Alder-PCA2 (increased leaf $\mathrm{P}$ and condensed tannins and decreased SLA) was positively related to the minimum annual precipitation and negatively related to the mean annual temperature. Finally, alder-PCA3, a surrogate of leaf lignin content, was positively influenced by $\mathrm{N}$ soil content and mean annual precipitation, whereas the annual range of temperature and the minimum annual precipitation had a negative effect on this leaf-quality variable.

\section{Decomposition}

Two leaf samples from each species dataset were selected to perform the decomposition experiment (Figs. 2, 3). These samples were selected for their maximum differences in nutrients and secondary compounds (Table 3), to represent both high and low leaf-litter quality (i.e., high nutrient and low secondary compounds in leaf content versus low nutrients and high secondary compounds in leaf content).

During the 17 days of immersion in the stream, the leaves lost $2-37 \%$ of their initial mass, and the alder leaves decomposed nearly twofold more rapidly than the oak leaves (Fig. 4). Microbial decomposition of high-quality oak leaves was significantly faster than that of low-quality leaves $(t=4.146, d f=8 ; P=0.003)$. There was a similar tendency for this in alder, but the difference was not significant $(t=-2.142, d f=8 ; P=0.065)$.

Consumption by shredders

The feeding experiment lasted for 8 days, with no mortality. Specimens of $S$. festiva consumed up to $230 \mu \mathrm{g}$ leaf material $\mathrm{day}^{-1} \mathrm{mg}^{-1}$ invertebrate mass, although some specimens did not feed. Consumption by S. festiva was

Table 3 Values of the quality variables for the leaf samples used in the decomposition and consumption experiments

\begin{tabular}{lrrrrrr}
\hline & \multicolumn{2}{l}{ Oak } & & & \multicolumn{2}{l}{ Alder } \\
\cline { 2 - 3 } \cline { 6 - 7 } & Qr04 & Qr37 & & Ag12 & Ag07 \\
\hline P leaf content (\%DM) & 0.16 & 0.02 & & 0.09 & 0.05 \\
N leaf content (\%DM) & 1.22 & 0.64 & & 2.95 & 1.66 \\
Condensed tannins leaf content (\%DM) & 8.47 & 19.45 & & 0.20 & 3.87 \\
Lignin leaf content (\%DM) & 34.18 & 42.41 & & 35.84 & 28.60 \\
Specific leaf area $\left(\mathrm{mm}^{2} \mathrm{mg}^{-1}\right)$ & 20.55 & 12.07 & & 19.06 & 8.58 \\
\hline
\end{tabular}

significantly higher on high-quality than on low-quality alder leaves (192 vs. $46 \mu \mathrm{g}$ leaf material day ${ }^{-1} \mathrm{mg}^{-1}$ invertebrate mass; $t=3.369, d f=14.14 ; P=0.005)$, but virtually identical for sets of specimens feeding on high-quality and low-quality oak litter samples $(t=0.447, d f=13.42$; $P=0.662$ ) (Fig. 5).

\section{Discussion}

Climate and leaf quality

We investigated the phenotypic variations in litter quality within two species in relation to environmental conditions, and tested whether these variations could affect microbial decomposition and invertebrate consumption. The PCA suggested that climate could affect leaf chemistry and physical properties. However, our first hypothesis that water stress (measured as low precipitation across the distributional area of both species) would result in tougher and chemically better defended leaves was not totally fulfilled, since for oak, the contents of condensed tannins and lignin tended to increase and SLA tended to decrease with increased precipitation. This was the opposite of our expectation, since plant physical defenses against water loss (thick cuticle and sclerophylly) are reported to increase

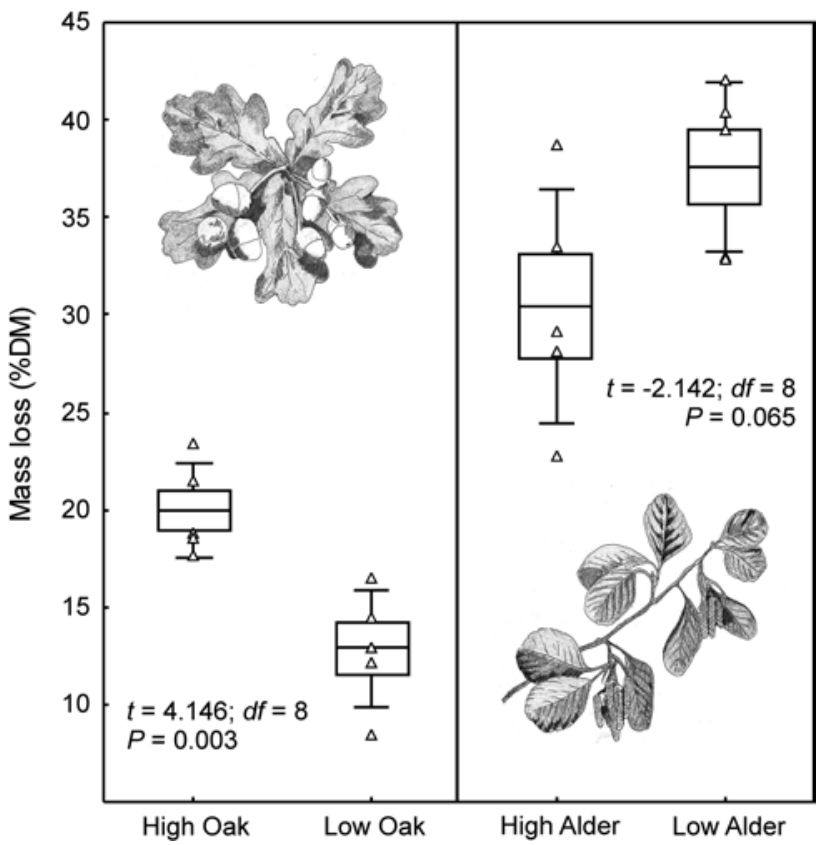

Fig. 4 Mass loss [\% dry matter; DM] of high- (QrO4 and Ag12) and low-quality ( $Q r 37$ and $\mathrm{AgO7}$ ) leaves of oak and alder incubated in a stream for 17 days. Lines represent means, boxes represent SEs, and whiskers represent SDs; $n=8$. Raw data are represented by triangles. See the codes in ESM (Table A1) for the origin of samples. For other abbreviations, see Figs. 2 and 3 


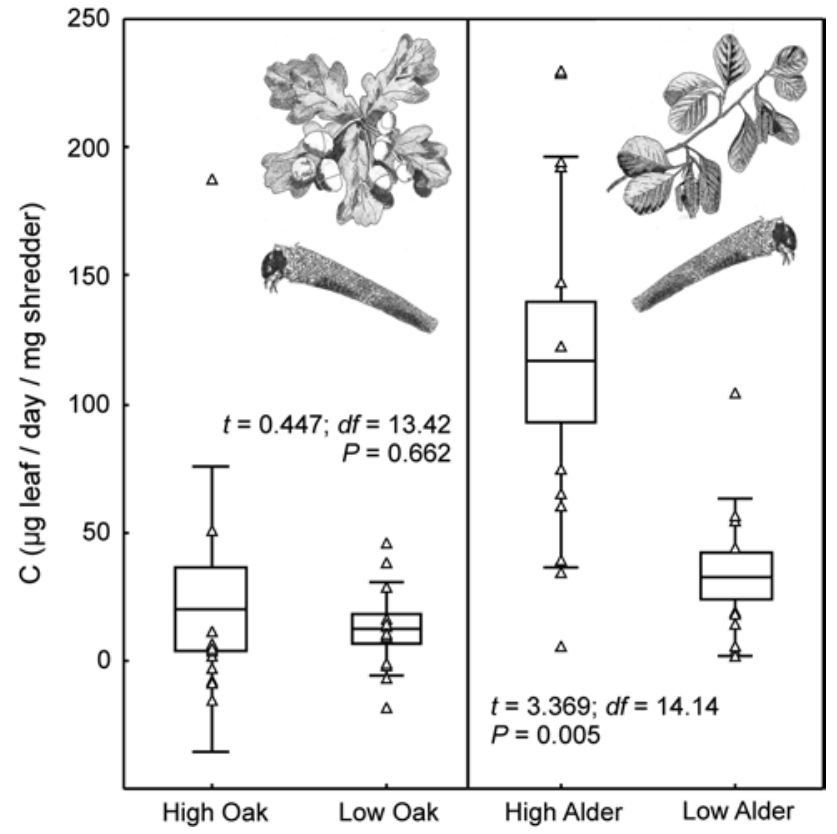

Fig. 5 Schizopelex festiva consumption rates on high- (Qr04 and Ag12) and low-quality (Qr37 and Ag 07) leaves of oak and alder, offered to the trichopterans during an 8-day experiment. Lines represent means, boxes represent SEs, and whiskers represent SDs; $n=24$. Raw data are represented by triangles. See the codes in ESM (Table A1) for the origin of samples. For abbreviations, see Figs. 2 and 3

with increased water stress (e.g., Pallardy 2008). Alder leaves from locations with high temperatures and wide temperature ranges indeed had high condensed tannins and low SLA (i.e., were tougher). The observation that alder leaves from locations with high temperatures also had lower $\mathrm{N}$ and $\mathrm{P}$ is consistent with the reported by (Chen et al. 2011).

Although unexpected, our results agree with the metadata analysis by Ordoñez et al. (2009) who concluded that climate has a small role in affecting variations in leaf traits compared with soil fertility, with SLA not related to any of the climate parameters evaluated (precipitation, temperature and evapotranspiration). In another study, Castro-Diez et al. (1998) reported increased N content in Pistacia spp. leaves toward the arid part of a gradient in Spain (i.e., $\mathrm{N}$ increase with water stress); and Cunningham et al. (1999) reported that low precipitation and nutrients in soil resulted in low SLA. These contradictory results suggest that: (1) phenotypic responses to climate is species-specific dependent, (2) climate alone is not enough to determine the traits related to the physical quality of leaves and (3) genetic variability is an unaccounted importance source of variability.

One potential limitation in our analysis is that we used mean precipitation and temperature values in the calculation. However, it is plausible that annual variation in these parameters could result in concomitant annual variation in the qualities of leaves and the resulting variations in litter.

Fertility and leaf quality

Our second expectation was that plants growing on nutrient-poor soils would produce leaves with low nutrient content. This was indeed observed for $\mathrm{P}$ in leaves from both oak and alder, which is consistent with other reports (e.g., Aerts and Chapin 2000; Chen et al. 2011; Han et al. 2011). However, leaf $\mathrm{N}$ was unrelated to soil $\mathrm{N}$ in both, alder and oak. The result was a surprise for alder, which is an $\mathrm{N}$-fixing species (Orfanoudakis et al. 2010). Positive (e.g., Han et al. 2011) and negative (Ordoñez et al. 2009) relationships between leaf $\mathrm{N}$ content and soil has been referred in the literature, suggesting that as with climate variables, other factors could be overriding the soil $\mathrm{N}$ effect.

The observed intraspecific variability in leaf traits can be explained by the environment, but also by the genotype. Those sources have shown to influence litter chemistry and can be large enough to cause differences in litter decomposition rates (LeRoy et al. 2007, 2012; Osier and Lindroth 2001). Some studies suggest that plant genotype is more important than soil nutrients in determining plant chemistry (e.g., Osier and Lindroth 2001) and a strong genetic component was also demonstrated for tannin levels in plants (Schweitzer et al. 2008 and references therein). We did not control for genotype differences, which may be responsible for a large part of the variation in the data. However, it can also be argued that particular plant genotypes are largely influenced and selected by local climate and local soil conditions. Common-garden experiments manipulating nutrients and water stress could be used to address the genetic component of trait variations (e.g., LeRoy et al. 2012).

The significance of the climate-leaf traitsdecomposition triad

$\mathrm{N}$ and condensed tannins are known to affect feeding rates of macro consumers (Azevedo-Pereira et al. 2006; Graça and Cressa 2010), decomposers and ultimately leaf-litter decomposition (Bakker et al. 2011; Cornwell et al. 2008; Makkonen et al. 2012; Waring 2012). We showed that variations in oak and alder leaves at the European continental scale are large enough to affect the rate at which the leaves are decomposed by microorganisms and consumed by shredders. However, microorganisms and shredders differed in their susceptibility to the same leaf traits. Microbial decomposition seemed to be particularly affected by high condensed tannin levels, whereas feeding by shredders seemed to be affected by low condensed tannin levels and low N. If our findings for these two species at the European continental scale can be extrapolated to a larger 
number of plant species and a wider range of environmental conditions, then the climate and soil have some control on the quality of leaves and consequently leaf litter and its decomposition by decomposers and shredders. The ecological implications of these relationships are that nutrient cycling through brown food webs may vary widely across geographic areas, and may explain the reported geographic variations in litter decomposition and the absence of shredders from some areas (Wantzen et al. 2008). For instance, in some tropical and Mediterranean streams, litter decomposition is slow and shredder invertebrates are absent or relatively unimportant (Boyero et al. 2011; Gonçalves et al. 2006, 2007). It is plausible that in these areas, the leaves are low quality, resulting from nutrient-poor soils and water and temperature stress.

\section{Implications under global changes}

Precipitation is predicted to decrease by $20 \%$ over Europe and temperature is predicted to increase by $2-4{ }^{\circ} \mathrm{C}$ in the next 80 years (IPCC 2007). Moreover, variations in temperature (heat waves) and precipitation are also likely to be more frequent (IPCC 2007). If interregional variation in the measured leaf traits are greatly related to the measured environmental parameters, we could predict ecological changes in nutrients cycling resulting from global nutrient and climate changes. This prediction is not simple because the same environmental factors may affect plant species differently. However, a common denominator of the two tested species here was an increase in condensed tannin content and decreased SLA (i.e., high toughness) in areas with high temperature variance and an increase leaf $P$ with increased Soil P. Such results may lead us to expect slow decomposition caused by global climate change. This effect can be balanced by increased $\mathrm{P}$ content in soils and nutrients (P and N) in the waters (e.g., Gulis et al. 2006) or may even be reinforced if nutrients are high enough to suppress the activities of decomposers (e.g., Woodward et al. 2012).

Acknowledgments We thank our colleagues across Europe for kindly sending us litter and soil samples: Adolfo Cordero (Spain), Amílcar Teixeira (Portugal), Andreas Bruder (Switzerland), Anna Romaní (Spain), Antonella Pasquale (Italy), Aranzazu Marcotegui (Spain), Arturo Elosegi (Spain), Bjorn Schaller (Germany), Brendan McKie (Sweden), Carlos Alexandre (Portugal), Cláudia Pascoal (Portugal), Christophe Piscart (France), Claus-G. Schimming (Germany), Daniela Dieter (Germany), Dean Jacobsen (Denmark), Ágostonné Szabó Edit (Hungary), Fernando Cobo (Spain), Franca Sangiorgio (Italy), Ian Dodkins (Portugal), Isabel Muñoz (Spain), Jan Herrmann (Sweden), Jeanette Schlief (Germany), Jessica Hines (Germany), Jesús Casas (Spain), Joerg Schaller (Germany), José Díez (Spain), Juanita Mora (Spain), Julia Toja (Spain), Julien Cornut (France), Kamila Fricová (Czech Republic), Loreto Rossi (Italy), Loraine Maltby (UK), Luz Boyero (Spain), Marcos González (Spain), Maria Leichtfried (Austria), Dinka Mária (Hungary), Marija (Lithuania), Mark Gessner (Germany), Maruxa Alvarez (Spain), Melanie
Fletcher (UK), Mike Dobson (UK), Nuno Formigo (Portugal), Nuria Bonada (Spain), Ondřej Simon (Czech Republic), Pedro Anastácio (Portugal), Pierre Marmonier (France), Rosa Fristad (Norway), Rui Cortes (Portugal), Salomé Almeida (Portugal), Samantha Huges (Portugal), Simone Varandas (Portugal), Sujitra Kosol (UK), Tadeuz Fleituch (Poland) and Verónica Ferreira (Portugal). We thank Maria Manuela Costa (Laboratório Química Agrícola e Ambiental) for chemical analysis of the soil samples, and Cristina Grela Docal (IMAR) for leaf $\mathrm{N}$ and $\mathrm{P}$ analysis and general laboratory assistance for other chemical analyses of leaves. The contribution of Robert Hall and two anonymous reviewers is gratefully acknowledged. This research was funded by the IMAR and the FCT through the project POCI/BIA-BDE/58297/2004.

\section{References}

Abelho M (2001) From litterfall to breakdown in streams: a review. Sci World J 1:656-680

Aerts R, Chapin F (2000) The mineral nutrition of wild plants revisited: reavaluation of processes and patterns. Adv Ecol Res 30:1-67

Allan D, Castillo M (2007) Stream ecology-structure and function of running waters. Springer, Dordrecht

Azevedo-Pereira HVS, Graça MAS, González JM (2006) Life history of Lepidostoma hirtum in an iberian stream and its role in organic matter processing. Hydrobiologia 559:183-192

Bakker MA, Carreño-Rocabado G, Poorter L (2011) Leaf economics traits predict litter decomposition of tropical plants and differ among land use types. Funct Ecol 25:473-483

Bärlocher F (2005) Leaf mass loss estimated by litter bag technique. In: Graça MAS, Bärlocher F, Gessner MO (eds) Methods to study litter decomposition: a practical guide. Springer, Dordrecht, pp 37-42

Boyero L et al (2011) Global distribution of a key trophic guild contrasts with common latitudinal diversity patterns. Ecology 92:1839-1848

Burnham KP, Anderson DR (2002) Model selection and multimodel inference: a practical information-theoretic approach. Springer, New York

Canhoto C, Graça MAS, Bärlocher F (2005) Feeding preferences. In: Graça MAS, Bärlocher F, Gessner MO (eds) Methods to study litter decomposition: a practical guide. Springer, Dordrecht, pp 297-302

Castro-Diez P, Villar-Salvador P, Perez-Rontome C, Maestro-Martinez M, Montserrat-Marti G (1998) Leaf morphology, leaf chemical composition and stem xylem characteristics in two Pistacia (Anacardiaceae) species along a climatic gradient. Flora 193:195-202

Chen Y, Han W, Tang L, Tang Z, Fang J (2011) Leaf nitrogen and phosphorus concentrations of woody plants differ in responses to climate, soil and plant growth form. Ecography 36

Cornwell WK, et al. (2008) Plant species traits are the predominant control on litter decomposition rates within biomes worldwide. Ecol Lett 11:1065-1071

Cunningham SA, Summerhayes B, Westoby M (1999) Evolutionary divergences in leaf structure and chemistry, comparing rainfall and soil nutrient gradients. Ecol Monogr 69:569-588

Doran JW, Jones AJ (1996) Methods for assessing soil quality. SSSA, Madison

Eaton AD, Clesceri LS, Greenberg AE (1995) (eds) Standard methods for the examination of water and wastewater, 19th edn. American Public Health Association, Washington, DC

Ferreira V, Encalada AC, Graça MAS (2012) Effects of litter diversity on decomposition and biological colonization of submerged litter in temperate and tropical streams. Freshwater Sci 31:945-962 
Gessner MO, Steiner D (2005) Acid butanol assay for Proanthocyanidins (condensed Tannins). In: Graça MAS, Bärlocher F, Gessner MO (eds) Methods to study litter decomposition: a practical guide. Springer, Dordrecht, pp 107-113

Goering HK, Van Soest PJ (1970) Forage fiber analysis (apparatus, reagents, procedures and some applications). Agricultural handbook. US Department of Agriculture, Washington, DC, pp 1-2

Gonçalves JF, Graca MAS, Callisto M (2006) Leaf-litter break-down in 3 streams in temperate, Mediterranean, and tropical Cerrado climates. J N Am Benthol Soc 25:344-355

Gonçalves JF, Graca MAS, Callisto M (2007) Litter decomposition in a Cerrado savannah stream is retarded by leaf toughness, low dissolved nutrients and a low density of shredders. Freshwater Biol 52:1440-1451

Graça MAS (2001) The role of invertebrates on leaf litter decomposition in streams: a review. Int Rev Hydrobiol 86:383-393

Graça MAS, Cressa C (2010) Leaf quality of some tropical and temperate tree species as food resource for stream shredders. Int Rev Hydrobiol 95:27-41

Graça MAS, Ferreira RCF, Coimbra CN (2001) Litter processing along a stream gradient: the role of invertebrates and decomposers. J N Am Benthol Soc 20:408-420

Gulis V, Ferreira V, Graça MAS (2006) Stimulation of leaf litter decomposition and associated fungi and invertebrates by moderate eutrophication: implications for stream assessment. Freshwater Biol 51:1655-1669

Han WX, Fang J, Reich P, Woodward FI, Wang Z (2011) Biogeography and variability of eleven mineral elements in plant leaves across gradients of climate, soil and plant functional type in China. Ecol Lett 14:788-796

Hijmans RJ, Cameron SE, Parra JL, Jones PG, Jarvis A (2005) Very high resolution interpolated climate surfaces for global land areas. Int J Climatol 25:1965-1978

Intergovernmental Panel on Climate Change (IPCC) (2007) Climate change 2007: synthesis report. Contribution of Working Groups I, II and III to the fourth assessment report of the Intergovernmental Panel on Climate Change. http://www.ipcc.ch/publications

Kaspari M, Garcia M, Harms K, Santana M, Wright S, Yavitt J (2008) Multiple nutrients limit litterfall and decomposition in a tropical forest. Ecol Lett 11:35-43

Krauss GJ, Sole M, Krauss G, Schlosser D, Wesenberg D, Barlocher F (2011) Fungi in freshwaters: ecology, physiology and biochemical potential. FEMS Microbiol Rev 35:620-651

Lecerf A, Chauvet E (2008) Intraspecific variability in leaf traits strongly affects alder leaf decomposition in a stream. Basic Appl Ecol 9:598-605

LeRoy CJ, Whitham TG, Wooley SC, Marks JC (2007) Within-species variation in foliar chemistry influences leaf-litter decomposition in a Utah river. J N Am Benthol Soc 26:426-438

LeRoy CJ, Wooley SC, Lindroth RL (2012) Genotype and soil nutrient environment influence aspen litter chemistry and in-stream decomposition. Freshwater Sci 31:1244-1253
Makkonen M et al (2012) Highly consistent effects of plant litter identity and functional traits on decomposition across a latitudinal gradient. Ecol Lett 15:1033-1041

Ordoñez JC, van Bodegom PM, Witte J-PM, Wright IJ, Reich PB, Aerts R (2009) A global study of relationships between leaf traits, climate and soil measures of nutrient fertility. Global Ecol Biogeogr 18:137-149

Orfanoudakis M, Wheeler CT, Hooker JE (2010) Both the arbuscular mycorrhizal fungus Gigaspora rosea and Frankia increase root system branching and reduce root hair frequency in Alnus glutinosa. Mycorrhiza 20:117-126

Osier TL, Lindroth RL (2001) Effects of genotype, nutrient availability, and defoliation on aspen phytochemistry and insect performance. J Chem Ecol 27:1289-1313

Pallardy SE (2008) Physiology of woody plants. Academic Press, Amsterdam

Pennings S, Carefoot T, Siska E, Chase M, Page T (1998) Feeding preferences of a generalist salt-marsh crab: relative importance of multiple plant traits. Ecology 79:1968-1979

Quinn GP, Keough MJ (2002) Experimental design and data analysis for biologists. Cambridge University Press, Cambridge

R Development Core Team (2008) R a language and environment for statistical computing. The $\mathrm{R}$ project for statistical computing. http://www.r-project.org

Reich PB, Oleksyn J (2004) Global patterns of plant leaf N and P in relation to temperature and latitude. Proc Natl Acad Sci USA 101:11001-11006

Rockström J et al (2009) A safe operating space for humanity. Nature 461:472-475

SAS (2007) JMP version 70 http://www.jmp.com

Schweitzer JA et al (2008) From genes to ecosystems: the genetic basis of condensed tannins and their role in nutrient regulation in a Populus model system. Ecosystems 11:1005-1020

StatSoft (2005) STATISTICA version $71 \mathrm{http}: / / \mathrm{www}$. statsoft.com

Trabucco A, Zomer RJ (2009) Global Aridity Index (Global-Aridity) and Global Potential Evapo-Transpiration (Global-PET) Geospatial database. CGIAR Consortium for Spatial Information. Published online, available from the CGIAR-CSI GeoPortal at: http://www.csi.cgiar.org

Vitousek PM et al (1997) Human alteration of the global nitrogen cycle: sources and consequences. Ecol Appl 7:737-750

Wantzen KM, Yule CM, Mathooko JM, Pringle C (2008) Organic matter processing in tropical streams. In: Dudgeon D (ed) Tropical stream ecology. Elsevier, Amsterdam

Waring BG (2012) A meta-analysis of climatic and chemical controls on leaf litter decay rates in tropical forests. Ecosystems 15:999-1009

Woodward G et al (2012) Continental-scale effects of nutrient pollution on stream ecosystem functioning. Science 336:1438-1440

Wright IJ, Reich PB, Westoby M (2001) Strategy shifts in leaf physiology, structure and nutrient content between species of highand low-rainfall and high- and low-nutrient habitats. Funct Ecol $15: 423-434$ 